\title{
Active Flux Based Finite Control Set Model Predictive Control of Synchronous Reluctance Motor Drives
}

\author{
Hazem Hadla, Sérgio Cruz \\ University of Coimbra and Instituto de Telecomunicações \\ Department of Electrical and Computer Engineering, Pólo II - Pinhal de Marrocos \\ Coimbra, Portugal \\ Tel: $+351 / 239.796 .272$ \\ Fax: $+351 / 239.796 .247$ \\ E-Mail: hrhadla@gmail.com,smacruz@ieee.org \\ URL: http://www.uc.pt
}

\section{Keywords}

«Synchronous motor», «Reluctance drive», «Direct torque and flux control», «Control of drive».

\begin{abstract}
This paper presents two new finite control set model predictive control (FCS-MPC) strategies for synchronous reluctance motor (SynRM) drives, using the active flux concept. Both control strategies guarantee a fast and independent control of the torque and active flux of the SynRM, in order to obtain a high performance drive. The first strategy relies on a more conventional implementation of a FCSMPC algorithm, which requires some effort to tune the weighting factors used in the cost function. The second control approach corresponds to a simplification of the first one, and allows a reduction of the calculation time associated to the predictions stage of the algorithm and, at the same time, avoids the use of weighting factors in the cost function. This allows to simplify the implementation of the control system, obtaining the same dynamic performance as with the first strategy. Experimental and simulation results verify the validity and effectiveness of the two proposed control schemes for SynRM drives. Furthermore, a state-of-the-art control technique like direct torque control is also considered in the paper, for performance comparison purposes.
\end{abstract}

\section{Introduction}

SynRMs have received increasing attention in the last years and now are looked as an alternative to induction motors (IMs) and permanent magnet synchronous motors (PMSMs) in some applications [1]. To achieve a high torque density, the SynRM has to operate at a high level of magnetic saturation. Hence, the phenomena of saturation and cross-magnetic saturation in this type of motor should be included not only in the mathematical model but also in its control system, in order to obtain a highperformance drive [2].Traditionally, two methods are available to control SynRM drives: direct torque control (DTC) and field oriented control (FOC) [3-6]. Nowadays, predictive control is seen as a promising alternative to those control schemes. In particular, FCS-MPC strategies are very attractive to be used in the field of power electronics and drives due to their easiness of implementation and the excellent dynamic performance granted to the system under control [7]. This type of control takes advantage of the discrete nature of the power converter that feeds the motor to solve the optimization problem, by evaluating the final state of the system for each possible actuation, in a prediction horizon. In [8], a predictive torque control (PTC) scheme for SynRMs was presented. The control algorithm, known as direct mean torque control (DMTC), is a kind of DTC that calculates the "switch on" time of the switches in a way that the steady-state value of the torque is directly reached at the end of the control cycle. In [9], a hierarchical direct predictive control (HDPC) strategy was proposed for SynRM drives, where the optimal voltage vector to be applied is obtained based on a hierarchical selection policy. In [10], an improved model-free predictive current control is presented to control the current of the SynRM and avoid the existence of current spikes that model-based predictive current control method involves [11]. 
In this paper, two FCS-MPC strategies are proposed for SynRM drives. The first control strategy combines the concept of active flux (AF) with the traditional philosophy of FCS-MPC strategies, in order to control the electromagnetic torque and the active flux of the SynRM independently. This control strategy is here called active flux FCS-MPC as it uses the AF concept and follows the conventional implementation steps of FCS-MPC. The second control strategy, called simplified active flux FCS-MPC, is a simplification of the first one. The simplification consists in the modification of the calculation steps associated with the prediction stage of the control algorithm, and the use of a more simple cost function, which does not require weighting factors. Simulation and experimental results validate the good dynamic performance of both control strategies, demonstrating the suitability of the developed control strategies for SynRM drives. In addition, a comparison of the performance of the proposed control techniques with DTC is also included.

\section{Mathematical Model of the SynRM}

\section{A. Model in $d q$ Axes}

The voltage and flux equations of a SynRM, in a $d q$ rotor reference frame, are given by

$$
\begin{aligned}
& u_{d}=R_{s} i_{d}+\frac{d \psi_{d}}{d t}-\omega_{e} \psi_{q} \\
& u_{q}=R_{s} i_{q}+\frac{d \psi_{q}}{d t}+\omega_{e} \psi_{d} \\
& \psi_{d}=L_{d}\left(i_{d}, i_{q}\right) i_{d} \\
& \psi_{q}=L_{q}\left(i_{d}, i_{q}\right) i_{q}
\end{aligned}
$$

where $u_{d}, u_{q}, i_{d}, i_{q}, \psi_{d}, \psi_{q}$ stand for the stator voltage, current and flux linkage components, respectively, $L_{d}$ and $L_{q}$ are the inductances of the stator windings along the $d q$ axes, $R_{s}$ is the stator winding resistance and $\omega_{e}$ is the rotor electrical angular speed.

The electromagnetic torque developed by the SynRM is given by

$$
T_{e}=\frac{3}{2} p\left(\psi_{d} i_{q}-\psi_{q} i_{d}\right)=\frac{3}{2} p\left(L_{d}-L_{q}\right) i_{d} i_{q}
$$

where $p$ is the number of pole pairs.

In a SynRM, the magnetic saturation and cross-magnetic saturation have a non-negligible influence on the dynamic behavior of the motor and on the performance of the whole drive system. Therefore, the values of $L_{d}$ and $L_{q}$ are stored in 2D lookup tables, as a function of $i_{d}$ and $i_{q}$, and are updated every control time step in the implementation of the control system [12].

\section{B. Active Flux Concept}

The active flux $\psi_{a}$ of an ac machine in general is the flux that multiplied by $i_{q}$ gives the developed electromagnetic torque [13]. For the specific case of a SynRM, the stator flux and the active flux are given by

$$
\begin{aligned}
& \underline{\psi}_{s}=\psi_{d}+j \psi_{q}=L_{d} i_{d}+j L_{q} i_{q} \\
& \underline{\psi}_{a}=\underline{\psi}_{s}-L_{q} \underline{i}_{s}=\psi_{d}+j \psi_{q}-L_{q}\left(i_{d}+j i_{q}\right)=\left(L_{d}-L_{q}\right) i_{d} .
\end{aligned}
$$

The electromagnetic torque developed by the SynRM is then given by

$$
T_{e}=\frac{3}{2} p \psi_{a} i_{q} .
$$

The previous equations show that $i_{d}$ is the active-flux-producing current component while $i_{q}$ is the torque-producing current component, allowing an independent control of the active flux and electromagnetic torque of the SynRM. Fig. 1 illustrates the steady-state vector diagram of a SynRM, with the active flux represented in red. 


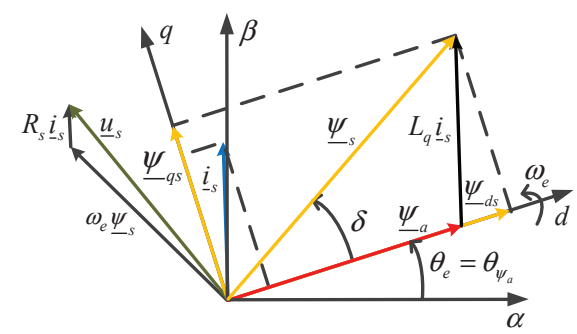

Fig. 1: Vector diagram of a SynRM operating in steady-state [13].

\section{Proposed Control Strategies for SynRMs}

The implementation of conventional FCS-MPC strategies usually consists in three main steps [14]: (1) measurement of the system state variables at instant $k ;(2)$ estimation of the variables that cannot be measured at instant $k+1$; (3) prediction of the future behavior of the system, at instant $k+2$, for all possible voltage vectors that can be applied by the inverter and choice for the system actuation the voltage vector that minimizes a certain defined cost function. One of the main advantages of FCSMPC is that several control targets, like current, torque, flux, etc, and different constraints can be imposed simultaneously [15]. On the other hand, if the cost function contains two or more variables with different nature (different units and/or different orders of magnitude), weighting factors need to be used. The tuning of these weighting factors is still one of the complex tasks of conventional FCSMPC, and an inappropriate choice of them will inevitably lead to a poor system performance or even to its inoperability [16]. Moreover, to use FCS-MPC in drives at an industrial level, some selfcommissioning capabilities are required and this can only be achieved by a proper analytical approach to choose the weighting factors or avoiding their use for example by considering a multiobjective ranking-based approach [16].

An implementation of FCS-MPC, called predictive torque control (PTC), was earlier presented in [7] and [17] to control the stator flux and torque of an induction motor drive. The first control strategy proposed in this paper for SynRM drives considers that the variables under control are the active flux and torque of the motor, being these two variables predicted two samples ahead of the current sampling time to account for the calculation delay.

\section{A. Active Flux FCS-MPC}

The general control diagram for the active flux FCS-MPC strategy proposed in this paper for SynRM drives is shown in Fig. 2.

The prediction model is based on equations (1)-(4). These equations are discretized using a forward Euler algorithm, thus allowing to estimate the currents $\hat{i}_{d}(k+1)$ and $\hat{i}_{q}(k+1)$ at instant $k+1$. Afterwards, for each one of the seven different voltage vectors that the two-level inverter can apply to the motor at instant $k+1$, the predicted currents for instant $k+2$ are calculated by

$$
\begin{gathered}
i_{d}^{p}(k+2)=\hat{i}_{d}(k+1)+\frac{T_{s}}{L_{d}}\left[u_{d}(k+1)-R_{s} \hat{i}_{d}(k+1)+\omega_{e} L_{q} \hat{i}_{q}(k+1)\right] \\
i_{q}^{p}(k+2)=\hat{i}_{q}(k+1)+\frac{T_{s}}{L_{q}}\left[u_{q}(k+1)-R_{s} \hat{i}_{q}(k+1)-\omega_{e} L_{d} \hat{i}_{d}(k+1)\right],
\end{gathered}
$$

Fig. 2: Block diagram of the proposed active flux FCS-MPC strategy for SynRMs. 
where $T_{s}$ is the discretization period.

Using the predicted stator currents for instant $k+2$, the active flux and torque can be predicted for instant $k+2$ by

$$
\begin{aligned}
& \psi_{a}^{p}(k+2)=\left(L_{d}-L_{q}\right) i_{d}^{p}(k+2) \\
& T_{e}^{p}(k+2)=\frac{3}{2} p \psi_{a}^{p}(k+2) i_{q}^{p}(k+2) .
\end{aligned}
$$

The final step of the control strategy is the evaluation of a cost function for each one of the seven different voltage vectors available. The cost function $g$ adopted here is the one shown in (13) and it has three terms: the first two terms represent the difference between the reference and the predicted values for the active flux and electromagnetic torque of the SynRM, while the third term $P$ accounts for the overcurrent protection of the system [17].

$$
g=\left(\frac{T_{e}^{*}-T_{e}^{p}(k+2)}{T_{n}}\right)^{2}+\lambda_{T}\left(\frac{\psi_{a}^{*}-\left|\psi_{a}^{p}(k+2)\right|}{\psi_{a n}}\right)^{2}+P\left(\underline{i}_{s}^{p}(k+2)\right)
$$

In (13), $\psi_{a n}$ and $T_{n}$ represent the rated values of the active flux and electromagnetic torque, $\lambda_{T}$ is the weighting factor that increases or decreases the relative importance of the torque error in relation to the active flux error, and $P\left(\underline{i}_{-s}^{p}(k+2)\right)$ is defined as follows:

$$
P\left(\underline{i}_{s}^{p}(k+2)\right)= \begin{cases}0 & \Leftarrow\left|\underline{i}_{s}^{p}(k+2)\right| \leq i_{\max } \\ \infty & \Leftarrow||_{-}^{p}(k+2) \mid>i_{\max }\end{cases}
$$

\section{B. Simplified Active Flux FCS-MPC}

Based on the conventional principles of FCS-MPC, the number of prediction calculations is directly related to the number of possible voltage vectors the inverter can apply to the motor. In case of a twolevel inverter, there are six active voltage vectors and two zero vectors available. Thus, the calculations for the predictions have to be performed seven times in each control cycle. This number increases exponentially if more complex power converters like multilevel converters or matrix converters feed the motor.

In order to reduce the computation time that conventional FCS-MPC algorithms involve, while maintaining the same control performance, it was proposed in [18] a simplified version of FCS-MPC applied to two- and three-level power converters. The basic idea of this method relies on avoiding the seven predictions of the currents at instant $k+1$ used in the conventional FCS-MPC strategy and calculate instead the reference voltage vector $u^{*}(k+1)$ that would make the two current components $i_{d}$ and $i_{q}$ reach their reference values at instant $k+2$. The voltage vector that will be applied to the motor at instant $k+1$ is the one that is closer to the reference vector $u^{*}(k+1)$. Using this procedure, only one set of calculations is performed in the predictions stage instead of the seven needed in the traditional approach. Moreover, the final process of choosing the actuating voltage vector is quite simple, decreasing the total control cycle time. Lastly, no weighting factors are needed, which significantly simplifies the implementation of FCS-MPC algorithms.

The basic concept of this simplified FCS-MPC, originally presented in [18] only for power converters and without delay compensation, is here explored and extended for the case of SynRM drives, including one step delay compensation feature. The overall control diagram of the proposed simplified active flux FCS-MPC strategy is shown in Fig. 3.

Based on the assumption that the variation of $T_{e}^{*}$ is very slow in comparison with the control cycle time $T_{s}$, one can assume that

$$
\begin{aligned}
& \psi_{a}^{*}(k+2)=\psi_{a}^{*}(k) \\
& T_{e}^{*}(k+2) \approx T_{e}^{*}(k) .
\end{aligned}
$$

By converting the reference values of the active flux and torque to their corresponding reference 


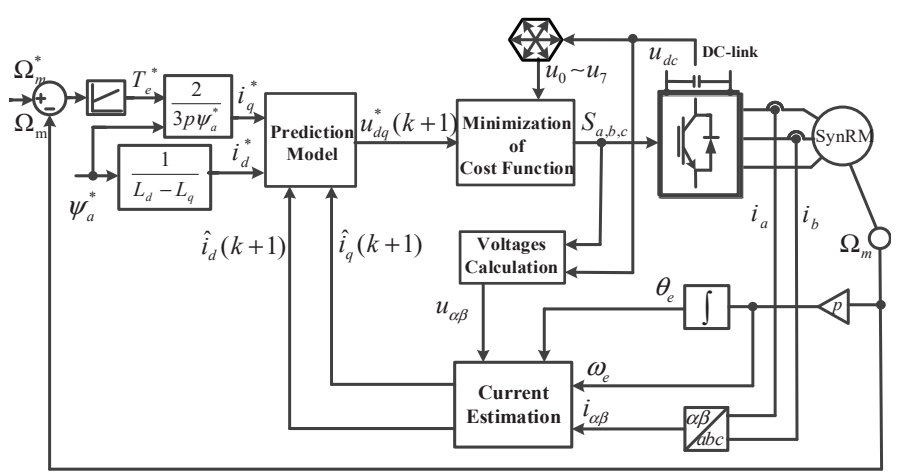

Fig. 3: Proposed simplified active flux FCS-MPC for SynRMs.

currents, using (11) and (12), one obtains

$$
\begin{aligned}
& i_{d}^{*}(k+2)=i_{d}^{*}(k) \\
& i_{q}^{*}(k+2) \approx i_{q}^{*}(k) .
\end{aligned}
$$

The main idea of the simplified active flux FCS-MPC approach relies on the calculation of the reference voltage vector that applied at instant $k+1$ makes the current reach the reference values given by (17)-(18) at instant $k+2$. The components of this reference voltage vector are given by (19)-(20) and were obtained by the manipulation and adaptation of (9)-(10), replacing the predicted currents by their corresponding reference values.

$$
\begin{aligned}
& u_{d}^{*}(k+1)=\frac{L_{d}}{T_{s}}\left[i_{d}^{*}(k+2)-\hat{i}_{d}(k+1)\right]+R_{s} \hat{i}_{d}(k+1)-\omega_{e} L_{q} \hat{i}_{q}(k+1) \\
& u_{q}^{*}(k+1)=\frac{L_{q}}{T_{s}}\left[i_{q}^{*}(k+2)-\hat{i}_{q}(k+1)\right]+R_{s} \hat{i}_{q}(k+1)+\omega_{e} L_{d} \hat{i}_{d}(k+1) .
\end{aligned}
$$

The final stage of the simplified active flux FCS-MPC strategy is just the evaluation of a very simple cost function, where no weighting factors need to be used, given by

$$
g=\left|u_{d}^{*}(k+1)-u_{d n}\right|^{2}+\left|u_{q}^{*}(k+1)-u_{q n}\right|^{2}, \quad n=0,1, . .6
$$

The vector to be applied to the motor at instant $k+1$ is the one that minimizes this cost function. The simplified active flux FCS-MPC strategy requires less computation time as instead of seven predictions for the currents, active flux and torque, a reference voltage vector is calculated only once and a much simpler cost function is evaluated in the end.

\section{DTC for SynRMs}

In this section, a brief description of the conventional DTC applied to SynRMs is presented for the sake of comparison with the aforementioned proposed control strategies. As it was mentioned in the introduction, the conventional DTC for SynRMs can achieve a very fast torque response.

The block diagram of the conventional DTC is shown in Fig. 4. In this control system, the stator flux

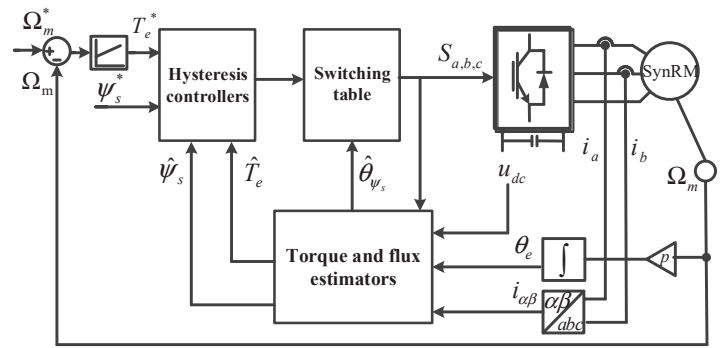

Fig. 4: Diagram of a DTC system for SynRMs. 
and torque are controlled with the aid of two hysteresis controllers and a switching table. The goal of DTC is to confine the flux and torque errors to small hysteresis bands by selecting the appropriate inverter switching state. In comparison with the control strategies proposed in this paper in Fig. 2 and Fig. 3, DTC also has a simple structure as all calculations are performed in a stationary reference frame. In spite of this feature, DTC exhibits some notable drawbacks, such as high torque ripple. Moreover, there is the need to select the width of the torque and flux hysteresis bands, which may not be a straightforward task.

\section{Simulation and Experimental Results}

To evaluate the performance of the two proposed control strategies, a simulation study was performed first, using a Simulink model of the drive system under analysis, and some experimental tests were carried out afterwards, in order to validate the proposed control systems.

\section{A. Simulation Results}

The simulation results presented in this subsection were obtained using the active flux FCS-MPC (AFFCS-MPC) and simplified AF-FCS-MPC strategies proposed in this paper. Results obtained with a DTC SynRM drive are also included for comparison purposes.

The parameters of the SynRM used in the tests are listed in Table I, which are identical to the ones of the motor used later on in the experimental tests.

The weighting factor $\lambda_{T}$ for the AF-FCS-MPC strategy was set as 0.2 . For the DTC strategy, the width of the hysteresis bands of the flux and torque controllers were set as 0.0092 and 0.3820 , respectively.

Table I: SynRM parameters.

\begin{tabular}{ll|ll}
\hline Rated power & $3 \mathrm{~kW}$ & Rated torque & $19.1 \mathrm{Nm}$ \\
\hline Rated voltage & $355 \mathrm{~V}$ & Rated speed & $1500 \mathrm{rpm}$ \\
\hline Rated current & $7.9 \mathrm{~A}$ & Rated efficiency & $90.4 \%$ \\
\hline Rated frequency & $50 \mathrm{~Hz}$ & Rotor inertia & $0.07941 \mathrm{Kg} \cdot \mathrm{m}^{2}$ \\
\hline Rated active flux & $0.69 \mathrm{~Wb}$ & Rated stator flux & $0.923 \mathrm{~Wb}$ \\
\hline
\end{tabular}

The simulation results shown in Fig. 5 illustrate the torque response of the SynRM drive, when it operates at $900 \mathrm{rpm}$, with rated flux, and is subjected to a torque reference step of $15 \mathrm{Nm}$. The system responses obtained with the AF-FCS-MPC, simplified AF-FCS-MPC, and DTC strategies are presented and their comparison demonstrates that the torque response of the proposed control strategies is very fast and comparable to DTC, with an approximate settling time of $0.9 \mathrm{~ms}$.
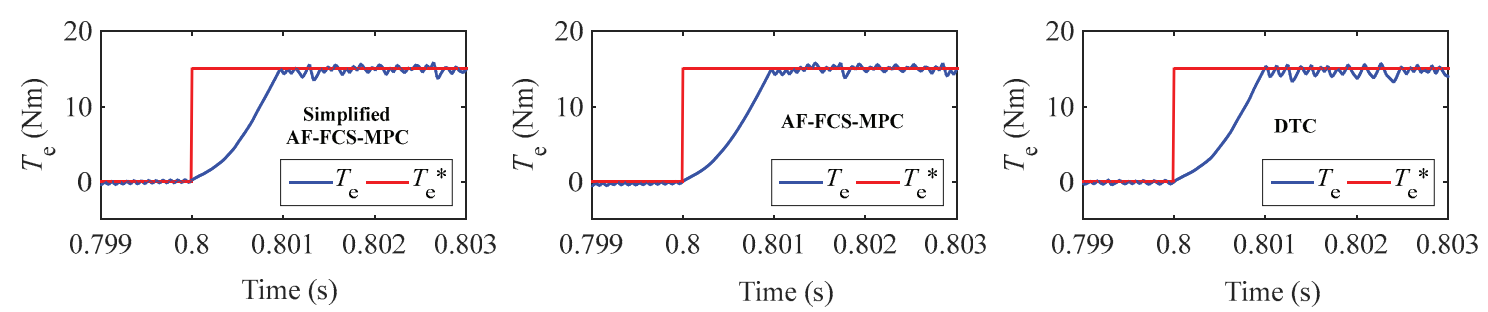

Fig. 5: Simulation results for a torque step of $15 \mathrm{Nm}$, with the SynRM running at a speed of $900 \mathrm{rpm}$, using the simplified AF-FCS-MPC, the AF-FCS-MPC, and the DTC strategies.

The simulation results shown in Fig. 6 illustrate the steady-state performance of the proposed control strategies and DTC when the drive operates at rated speed $(1500 \mathrm{rpm})$ with $50 \%$ of full-load torque. From top to bottom, the results show the electromagnetic torque, flux (active or stator flux, which were set equal to their rated values) and the stator current waveforms.

As can be seen, the DTC strategy exhibits higher torque oscillations in comparison with the proposed predictive control strategies. Comparing the two proposed control strategies, they exhibit almost identical torque, flux and current ripples. It is worth mentioning that the results obtained for the 

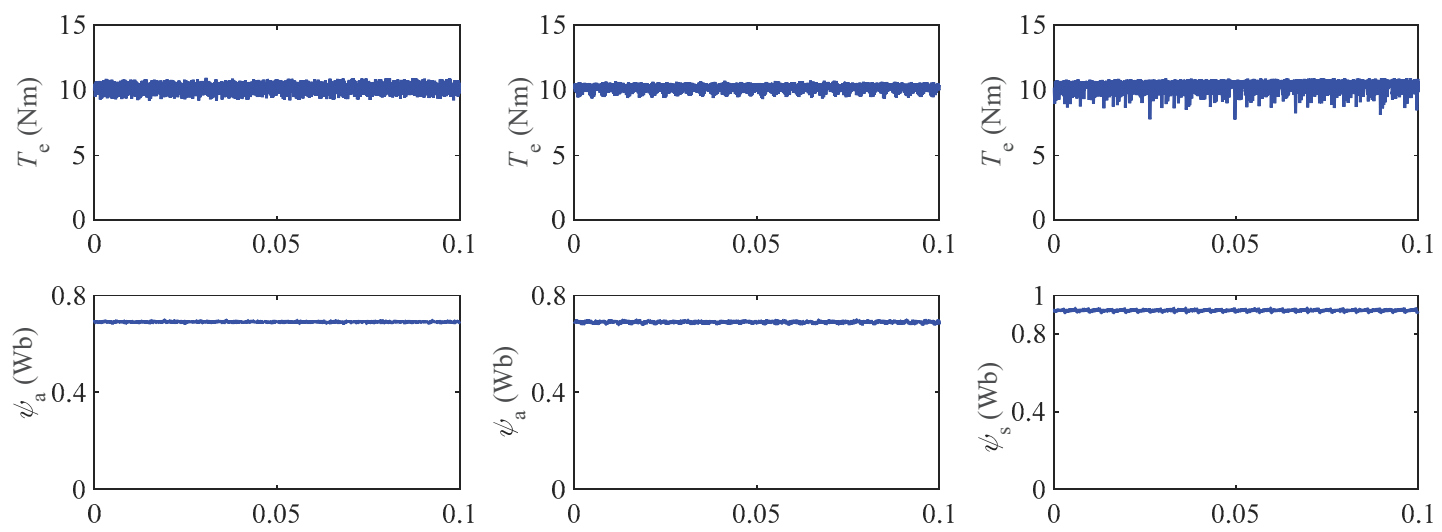

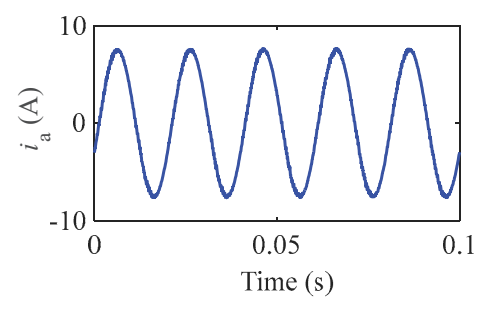

(a)

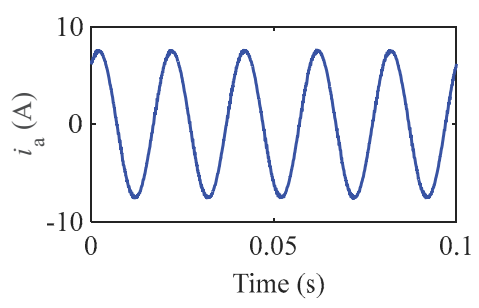

(b)

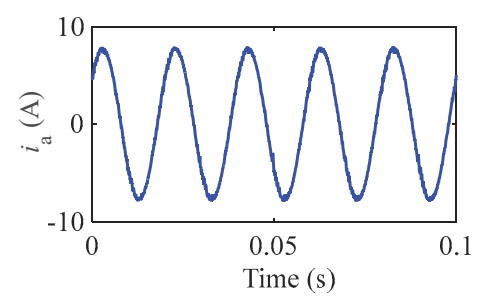

(c)

Fig. 6: SynRM drive running in steady-state, at $1500 \mathrm{rpm}$ with $50 \%$ of load torque: (a) simplified AFFCS-MPC; (b) AF-FCS-MPC; (c) DTC.

AF-FCS-MPC and DTC control strategies required a tedious work of finding a suitable weighting factor and optimal values for the torque and flux hysteresis bands in order to obtain the desired control performance. On the contrary, the simplified AF-FCS-MPC does not require such tuning effort, being preferred in practice due to its easy commissioning.

\section{B. Experimental Results}

The experimental setup used to validate the simulation results consists in a dSPACE 1103 platform that controls the SynRM drive system comprising a high efficiency (IE 4) 3-phase, 4-pole SynRM coupled to an auxiliary $7.5 \mathrm{~kW}$ induction motor fed by an inverter, to act as a controlled mechanical load to the SynRM (Fig. 7). An incremental encoder with $1024 \mathrm{ppr}$ was mounted on the shaft of the two machines to measure their rotor position. Due to the limited space available, only experimental results obtained with the AF-FCS-MPC and simplified AF-FCS-MPC control strategies are included in the paper.

Some control parameters related to the practical implementation of the control strategies are listed in Table II.

The experimental results presented in Fig. 8 show the steady-state performance of the AF-FCS-MPC and simplified AF-FCS-MPC strategies when the SynRM runs with a constant load torque of $10 \mathrm{Nm}$ at a speed of $900 \mathrm{rpm}$. For both control strategies, the motor current waveforms exhibit low ripple and have a very low total harmonic distortion (THD).

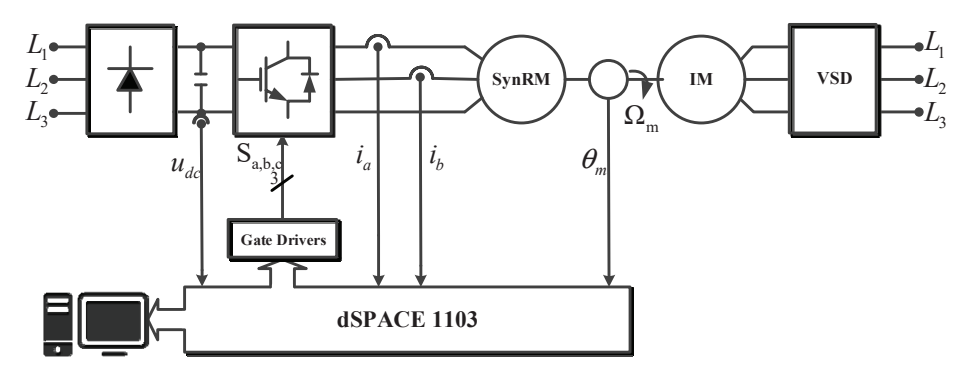

Fig. 7: Configuration of the experimental setup. 
Table II: Main control parameters used for the two control strategies.

\begin{tabular}{|c|c|c|c|}
\hline \multicolumn{2}{|c|}{ Parameter } & AF-FCS-MPC & Simplified AF-FCS-MPC \\
\hline & $T_{s}$ & $40 \mu \mathrm{s}$ & $40 \mu \mathrm{s}$ \\
\hline \multirow{3}{*}{ Speed loop } & $T_{\text {speed }}$ & $25 \times 40 \mu \mathrm{s}$ & $25 \times 40 \mu \mathrm{s}$ \\
\hline & $K_{p}$ & 0.15 & 0.15 \\
\hline & $T_{i}$ & 0.66 & 0.66 \\
\hline & $\lambda_{T}$ & 0.2 & - \\
\hline
\end{tabular}
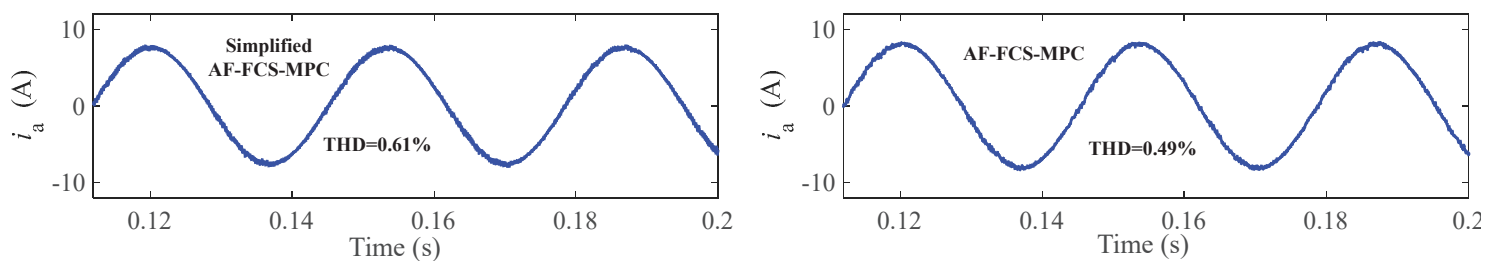

Fig. 8: Experimental current waveforms and current THD with the SynRM drive running at $900 \mathrm{rpm}$ with a load torque of $10 \mathrm{Nm}$.

The performance of the two control strategies was also evaluated under transient conditions. The SynRM drive was operated in torque control mode by disconnecting the speed controller and setting manually the value of the reference torque, while the auxiliary induction motor drive, acting as a controlled load, was run in speed control mode in order to maintain the speed roughly constant.

A torque step of $10 \mathrm{Nm}$ was then imposed to the SynRM while it was running at $900 \mathrm{rpm}$, being the obtained results shown in Fig. 9. A zoomed version of the torque response in the vicinity of $t=0.3 \mathrm{~s}$ is shown in Fig. 10.

These results show that both control strategies have a remarkable fast torque response. A variation of roughly $50 \%$ of rated torque is achieved in approximately $0.4 \mathrm{~ms}$, which is a very fast torque response. A motor speed reversal maneuver has also been performed in order to compare the performance of both control strategies in a wide speed range, under transient conditions. This test was conducted with the SynRM initially running at $1000 \mathrm{rpm}$ with a load torque of $10 \mathrm{Nm}$. The experimental results
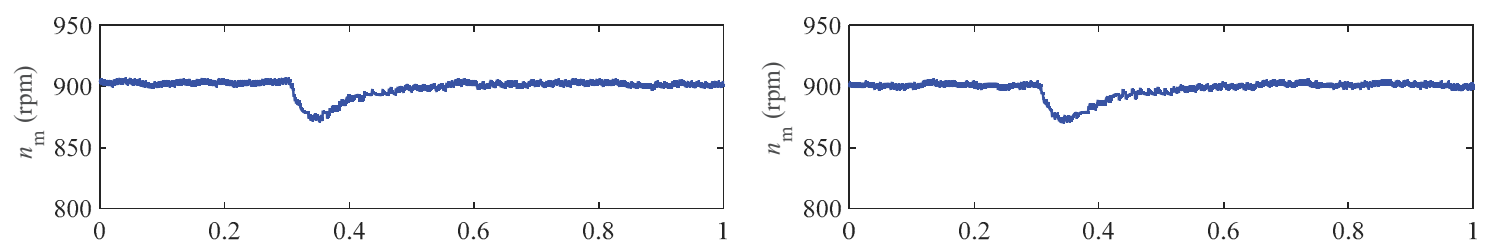

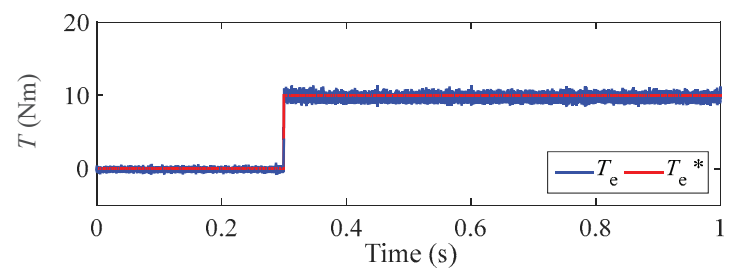

(a)

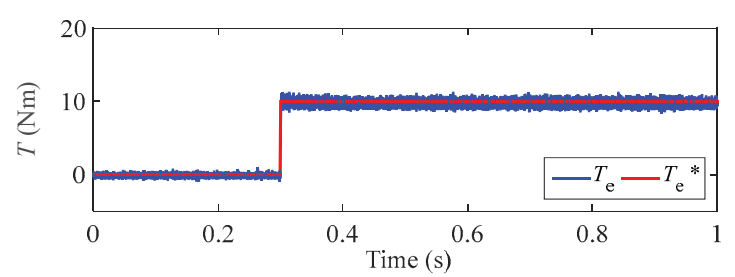

(b)

Fig. 9: Experimental results for a torque step of $10 \mathrm{Nm}$, with the SynRM running at a speed of 900 rpm: (a) AF-FCS-MPC, (b) simplified AF-FCS-MPC.
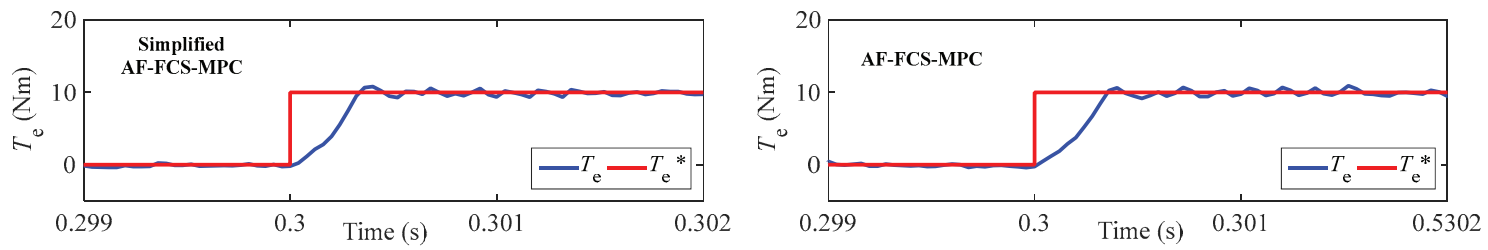

Fig. 10: Zoom of the torque response, shown in Fig. 7, for the proposed control strategies. 
obtained for the rotor speed, torque, and stator current of the SynRM using the AF-FCS-MPC and simplified AF-FCS-MPC strategies are presented in Fig. 11.
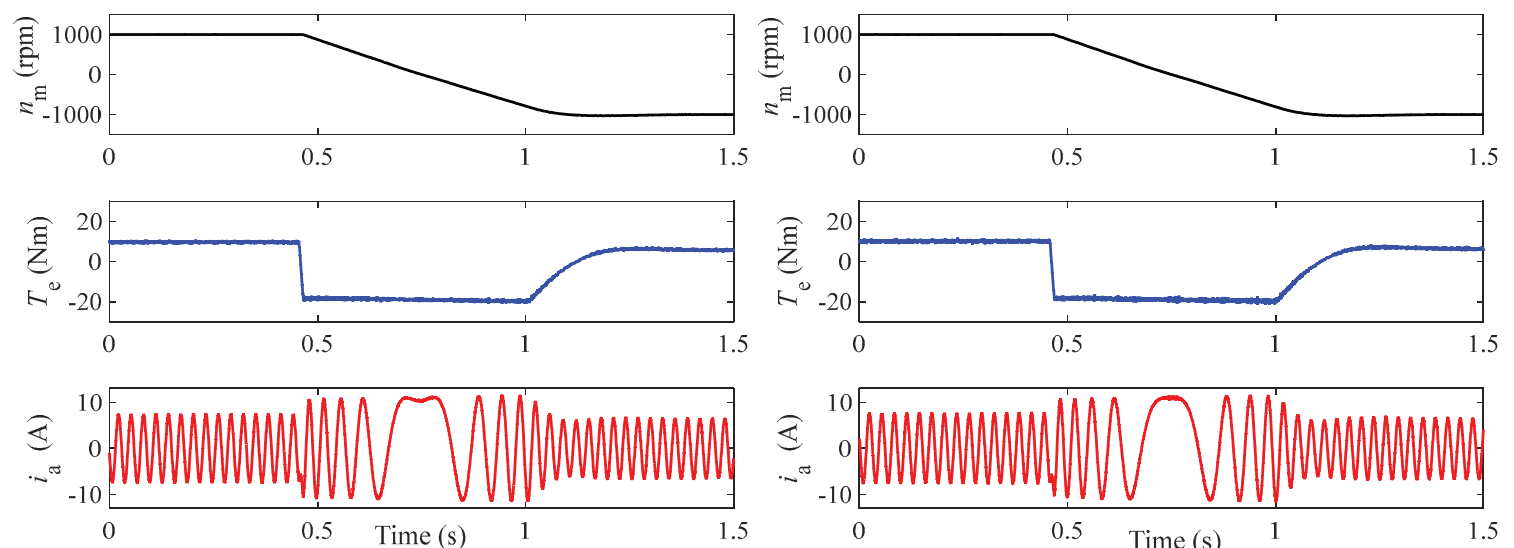

(a)

(b)

Fig. 11: Rotor speed, torque and stator current waveforms of the SynRM during a speed reversal maneuver, under a load torque of $10 \mathrm{Nm:} \mathrm{(a)} \mathrm{AF-FCS-MPC;} \mathrm{(b)} \mathrm{simplified} \mathrm{AF-FCS-MPC.}$

The results demonstrate that the simplified AF-FCS-MPC leads to a very good dynamic performance, equivalent to the one obtained with the conventional AF-FCS-MPC under transient conditions. Altogether, these results lead to the conclusion that both control strategies allow to obtain a highperformance SynRM drive under all operating conditions.

The simplified AF-FCS-MPC offers an additional interesting feature, which is the possibility of providing the reference voltages applied to the motor. This can be helpful for example in the implementation of rotor position estimation techniques based on high-frequency voltage signal injection. Regarding the computational cost in the implementation of the proposed control strategies, it was found that the execution time of the simplified AF-FCS-MPC strategy was $19 \mu$ s while for the AF-FCS-MPC strategy was $25 \mu \mathrm{s}$. The low computational time of the simplified AF-FCS-MPC is one of its advantages.

Finally, a brief comparison of some features of the two proposed control strategies is shown in Table III.

Table III: Comparison between the AF-FCS-MPC and the simplified AF-FCS-MPC strategies.

\begin{tabular}{c|c|c}
\hline Feature & AF-FCS-MPC & Simplified AF-FCS-MPC \\
\hline Weighting factors & Yes & No \\
\hline Computational cost & Higher & Lower \\
\hline Stator current THD & Low & Low \\
\hline
\end{tabular}

\section{Conclusion}

Two new active flux based finite control set model predictive control strategies were proposed in this paper for SynRM drives, thus combining the advantages of the active flux concept with the fast response that characterizes finite control set model predictive control strategies. Both strategies proved to be able to achieve a very good dynamic performance, comparable to the one obtained with direct torque controlled drives but with less torque ripple.

The experimental results show that the proposed control strategies perform very well, in steady-state and in transient conditions, allowing to obtain very low values for the current THD factor. Nonetheless, the simplified AF-FCS-MPC strategy has several advantages over the more conventional AF-FCS-MPC due to the following aspects:

- The cost function does not have weighting factors to be tuned;

- The predictions stage of the control strategy is significantly simplified, thus reducing the control execution time, while maintaining the same performance of the AF-FCS-MPC strategy. 
Finally, it can be stated that the active flux concept is suitable to be used with both control strategies and can be explored to track the position of the rotor of the motor, as the position of the active flux vector coincides at all time with the rotor $d$-axis, hence simplifying significantly the development of a future sensorless SynRM drive based on the proposed control strategies.

\section{References}

[1] S. Taghavi and P. Pillay, "A Sizing Methodology of the Synchronous Reluctance Motor for Traction Applications," IEEE Journal Power Electron., vol. 2, pp. 329-340, 2014.

[2] J. B. Im, W. Kim, K. Kim, C. S. Jin, J. H. Choi, and J. Lee, "Inductance Calculation Method of Synchronous Reluctance Motor Including Iron Loss and Cross Magnetic Saturation," IEEE Trans. Magnet., vol. 45, pp. 2803-2806, 2009.

[3] E. Daryabeigi, H. Abootorabi Zarchi, G. R. Arab Markadeh, J. Soltani, and F. Blaabjerg, "Online MTPA Control Approach for Synchronous Reluctance Motor Drives Based on Emotional Controller," IEEE Trans. Power Electron., vol. 30, pp. 2157-2166, 2015.

[4] Z. Xinan, G. H. B. Foo, D. M. Vilathgamuwa, and D. L. Maskell, "An Improved Robust Field-Weakeaning Algorithm for Direct-Torque-Controlled Synchronous-Reluctance-Motor Drives," IEEE Trans. Ind. Electron., vol. 62, pp. 3255-3264, 2015.

[5] Y. Inoue, S. Morimoto, and M. Sanada, "A Novel Control Scheme for Maximum Power Operation of Synchronous Reluctance Motors Including Maximum Torque Per Flux Control," IEEE Trans. Ind. Appl., vol. 47, pp. 115-121, 2011.

[6] A. P. Goncalves, S. M. A. Cruz, F. J. T. E. Ferreira, A. M. S. Mendes, and A. T. de Almeida, "Synchronous Reluctance Motor Drive for Electric Vehicles Including Cross-Magnetic Saturation," in IEEE Vehicle Power and Propulsion Conference, Coimbra, Portugal, 2014, pp. 1-6.

[7] J. Rodriguez, R. M. Kennel, J. R. Espinoza, M. Trincado, C. A. Silva, and C. A. Rojas, "High-Performance Control Strategies for Electrical Drives: An Experimental Assessment," IEEE Trans. Ind. Electron., vol. 59, pp. 812-820, 2012.

[8] R. Morales-Caporal and M. Pacas, "A Predictive Torque Control for the Synchronous Reluctance Machine Taking Into Account the Magnetic Cross Saturation," IEEE Trans. Ind. Electron., vol. 54, pp. 1161-1167, 2007.

[9] R. Antonello, M. Carraro, L. Peretti, and M. Zigliotto, "Hierarchical Scaled-States Direct Predictive Control of Synchronous Reluctance Motor Drives," IEEE Trans. Ind. Electron., 2016.

[10] C. K. Lin, J. t. Yu, Y. S. Lai, and H. C. Yu, "Improved Model-Free Predictive Current Control for Synchronous Reluctance Motor Drives," IEEE Trans. Ind. Electron., vol. 63, pp. 3942-3953, 2016.

[11] C. Lin, J. Yu, H. Yu, and Y. Lo, "Simplified model-free predictive current control for synchronous reluctance motor drive systems," in IEEE Magnet. Conf., Beijing, China, 2015.

[12] Á. Oliveira, D. Cavaleiro, R. Branco, H. Hadla, and S. Cruz, "An encoderless high-performance synchronous reluctance motor drive," in IEEE Conf. Ind. Technology, 2015, pp. 2048-2055.

[13] I. Boldea, M. C. Paicu, and G. Andreescu, "Active Flux Concept for Motion-Sensorless Unified AC Drives," IEEE Trans. Power Electron., vol. 23, pp. 2612-2618, 2008.

[14] J. Rodriguez, M. P. Kazmierkowski, J. R. Espinoza, P. Zanchetta, H. Abu-Rub, H. A. Young, et al., "State of the Art of Finite Control Set Model Predictive Control in Power Electronics," IEEE Trans. Ind. Informat., vol. 9, pp. 1003-1016, 2013.

[15] P. Cortes, S. Kouro, B. La Rocca, R. Vargas, J. Rodriguez, J. I. Leon, et al., "Guidelines for weighting factors design in Model Predictive Control of power converters and drives," in International Conf. Ind. Technology, Gippsland, Australia, 2009, pp. 1-7.

[16] C. A. Rojas, J. Rodriguez, F. Villarroel, J. R. Espinoza, C. A. Silva, and M. Trincado, "Predictive Torque and Flux Control Without Weighting Factors," IEEE Trans. Ind. Electron., vol. 60, pp. 681-690, 2013.

[17] H. Miranda, P. Cortes, J. I. Yuz, and J. Rodriguez, "Predictive Torque Control of Induction Machines Based on State-Space Models," IEEE Trans. Ind. Electron., vol. 56, pp. 1916-1924, 2009.

[18] X. Changliang, L. Tao, S. Tingna, and S. Zhanfeng, "A Simplified Finite-Control-Set Model-Predictive Control for Power Converters," IEEE Trans. Ind. Informat., vol. 10, pp. 991-1002, 2014. 